\title{
Continued increase in prevalence of $r$-type opacities among underground coal miners in the USA
}

\author{
Noemi B Hall, ${ }^{\circledR}$ David J Blackley, Cara N Halldin, A Scott Laney
}

Respiratory Health Division, National Institute for Occupational Safety and Health, Morgantown, West Virginia, USA

\section{Correspondence to} Dr Noemi B Hall, Respiratory Health Division, National Institute of Occupational Safety and Health, Morgantown, WV 26505-2888, USA; nhall@cdc.gov

Received 3 January 2019 Revised 8 April 2019 Accepted 14 April 2019 Published Online First 25 April 2019

\section{Check for updates}

(C) Author(s) (or their employer(s)) 2019. No commercial re-use. See rights and permissions. Published by BMJ.

To cite: Hall NB,

Blackley DJ, Halldin CN,

et al. Occup Environ Med

2019:76:479-481.
ABSTRACT
Introduction Respirable crystalline silica exposure

has been implicated in the resurgence of coal workers' pneumoconiosis (CWP) in the USA. A 2010 report found an increasing prevalence of r-type opacities, which are associated with silicosis lung pathology, on the radiographs of working underground coal miners in central Appalachia. This analysis updates that report by assessing the prevalence of r-type opacities during 2010-2018 compared with earlier decades.

Methods Data from the Coal Workers' Health Surveillance Program were used to calculate the prevalence of r-type opacities on radiographs of working underground coal miners. The data were restricted to radiographs taken during 1 January 1980 to 15 September 2018. The presence of r-type opacities was defined as an r-type classification for either the primary or secondary shape/size of small opacities. Prevalence ratios for r-type opacities were calculated using log binomial regression.

Results Radiograph classifications for 106506 miners were included in analysis. For the USA overall, the prevalence of r-type opacities among miners with radiographs taken during 2010-2018 compared with 1980-1989 has increased (PR 2.4; 95\% Cl 1.9 to 3.0). For central Appalachia, the proportion of r-type opacities observed increased when comparing 1980-1989 to 2010-2018 (PR 6.0; 95\% Cl 4.6 to 7.9).

Conclusions The prevalence of r-type opacities on the radiographs of Appalachian underground coal miners continues to increase, implicating exposure to crystalline silica in respirable coal mine dust. The current findings underscore the importance of monitoring and controlling exposure to silica in coal mines.

\section{INTRODUCTION}

The USA is experiencing an unprecedented resurgence of the most severe form of coal workers' pneumoconiosis (CWP), especially among miners working in central Appalachia, defined as the states of Kentucky, Virginia and West Virginia. A 2010 study reported increases in the proportion of chest radiographs from central Appalachian coal miners with r-type small opacities, an abnormality associated with silicosis lung pathology. ${ }^{1}$ The report hypothesised that the rising prevalence and severity of pneumoconiosis in the region was associated with respirable crystalline silica exposure. Respirable crystalline silica is more toxic than coal dust and is associated with increased pulmonary inflammation, ${ }^{2}$ and this finding underscored the need for effective silica dust monitoring and control in US

\section{Key messages}

What is already known about this subject?

- r-Type opacities are associated with silicosis. A report was first published in 2010 showing that prevalence of r-type opacities had increased since the 1980s among underground coal miners in the USA.

\section{What are the new findings?}

- The prevalence of r-type opacities among underground coal miners of central Appalachia continues to increase.

\section{How might this impact on policy or clinical} practice in the foreseeable future?

- These findings may increase scrutiny on current dust monitoring practices and place increased focus on efforts to develop continuous personal dust monitors specifically for respirable crystalline silica dust.

coal mines. Subsequent lung pathology research has highlighted the role of silica and silicates in rapidly progressive CWP. ${ }^{3}$ Studies continue to identify increasing prevalence and severity of $\mathrm{CWP}^{4}$ and its associated consequences, including compensated disability claims, ${ }^{5}$ lung transplantation ${ }^{6}$ and premature mortality. ${ }^{7}$ Our aim is to update prevalence trends for r-type small opacities identified on chest radiographs of US underground coal miners, including a comparison between central Appalachia and the rest of the nation.

\section{METHODS}

Working underground coal miners who participated in the National Institute for Occupational Safety and Health (NIOSH)-administered Coal Workers' Health Surveillance Program (CWHSP) during 1 January 1980 to 15 September 2018 were included for analysis. Demographic information, occupational history (including the state where the miner was employed) and chest radiograph classification data were derived from each miner's most recent CWHSP encounter.

Radiographs were classified by at least two NIOSH-certified B Readers according to the guidelines for the use of the International Labour Office International Classification of Radiographs of Pneumoconioses and regulations found at 42 Code of Federal Regulations (CFR) $37 .^{8}$ If small opacities are identified on a radiograph, then a B Reader selects their corresponding shape/size. Small, 
rounded opacities with diameters of $3-10 \mathrm{~mm}$ are classified as r-type and are associated with silicosis lung pathology. ${ }^{39}$ For this study, the presence of r-type opacities was defined as at least one B Reader selection of r-type for either the primary or secondary shape/size of small opacities on the radiograph. Prevalence ratios comparing the prevalence of r-type opacities by decade were calculated using log-binomial regression using SAS 9.4.

\section{RESULTS}

A total of 106506 working underground coal miners participated in the CWHSP at least once during 1 January 1980 to 15 September 2018, and the most recent radiographic classification for each miner was included in analysis. A majority of miners were men (97.3\%) and white (96.2\%), and 46.2\% worked in central Appalachia at the time the radiograph was obtained. Median age at the time of radiograph was 37 years. Median miner age during 1980-1989, 1990-1999, 2000-2009 and 2010-2018 was 33, 43, 44 and 37, respectively.

A total of 8514 radiographs had opacities present and primary shape/size classification information and 7581 radiographs had opacities present and secondary shape/size information, for a total of 8520 radiographs with opacities present and either primary or secondary shape/size classification information available. Of these 8520 radiographs, 532 were classified as having r-type opacities. These 532 radiographs with primary and/or secondary r-type opacities $(0.5 \%$ of all radiographs) are the focus of this analysis.

In the USA, the proportion of radiographs with r-type opacities has increased each decade since 1980 , with a greater than twofold overall increase for 2010-2018 compared with 19801989 (PR 2.4; 95\% CI 1.9 to 3.0). However, this increase was not observed when excluding radiographs from miners in central Appalachian states (PR 0.8; 95\% CI 0.5 to 1.2 ) (figure 1). When analysis was restricted to miners from Kentucky, Virginia and West Virginia, there was a significant increase in the prevalence of r-type opacities across the entire study period (PR 6.0; 95\% CI 4.6 to 7.9 ), including a significant increase when comparing 2010-2018 with 2000-2009 (PR 1.3; 95\% CI 1.1 to 1.7 ) and comparing 2010-2018 with 1990-1999 (PR 3.1; 95\% CI 2.2 to 4.4).

Mining tenure information was not uniformly available. However, miner age was highly correlated with mining tenure in this population, and adjusted analyses found that age did not



Figure 1 Percentage of $\mathrm{r}$-type opacities, by region and decade, 19802018. fully explain long-term increases in the prevalence of r-type opacities. When including age as a covariate in the model, the prevalence of r-type opacities in central Appalachia increased significantly across the entire study period (PR 2.5; 95\% CI 1.9 to 3.4), including a significant increase from 2000-2009 to 2010-2018 (PR 1.2; 95\% CI 1.1 to 1.6).

\section{DISCUSSION}

The prevalence of r-type opacities on the radiographs of coal miners in central Appalachia has increased each decade since 1980. This finding could help to explain the sharp increases in the prevalence and severity of pneumoconiosis observed in this region since the late 1990s. Though the radiographic classification of r-type opacities does not constitute a clinical diagnosis of silicosis, these rounded opacities have been associated with silicosis through pathology. ${ }^{39}$

Thin-seam coal mining is common in Appalachia. This practice can involve cutting large amounts of silica-bearing rock outside the coal seam to maintain haulage clearances. ${ }^{10}$ A recent study based on interviews of 19 coal miners from a clinic-based cluster of 416 miners with progressive massive fibrosis in Virginia found that $13(68 \%)$ participants reported regularly cutting 12 inches or more of rock while mining coal during their careers. Participants also described using continuous miner machines to cut slopes and ventilation shafts through pure sandstone, working downwind of dust-generating equipment, and improper use of dust monitoring and control equipment. ${ }^{11}$ A total of 122 (29\%) of the 416 radiographs from these miners were classified as having r-type opacities. ${ }^{11} 12$

Previous reports using CWHSP data have shown that participation bias and B Reader classifications are not likely to influence any temporal trends in CWP reported by the CWHSP. ${ }^{13}$

There is no cure for pneumoconiosis and for an increasing number of coal miners, lung transplantation becomes the medical intervention of last resort. ${ }^{6}$ The public health goal must be prevention, accomplished through effective coal mine dust control and early identification of disease. Although dust exposure data were not available for the miners in this analysis, coal mine dust is the sole cause of pneumoconiosis in coal miners.

Traditional respirable crystalline silica exposure monitoring in US coal mines requires dust samples to be sent to commercial laboratories for analysis, and results are not available for days or weeks. Newly developed software implemented as part of a field-based monitoring approach enhances coal mine operators' ability to conduct accurate end-of-shift respirable crystalline silica monitoring, which could help operators quickly address exposure sources and prevent further exposure for miners on subsequent shifts. ${ }^{14}$

Early disease detection and secondary prevention can also be improved. Through the CWHSP, working coal miners who participate in screening are confidentially informed of their respiratory health status, and if radiographic pneumoconiosis is identified, they have a legal right to transfer to a less dusty position at the mine while retaining their regular rate of pay. However, these forms of secondary prevention of CWP are underutilised. A recent study showed that $39 \%$ of miners who first applied for federal black lung benefits during 2000-2016 had never participated in the CWHSP during their career. ${ }^{15}$ Among miners who did participate in the CWHSP during 1986-2016 and were found to be eligible for transfer rights, only $14.4 \%$ chose to exercise their transfer right. ${ }^{16}$ In Kentucky and Virginia, two states with the highest prevalence of CWP, participation rates in the job transfer programme were $9.8 \%$ and $8.9 \%$, respectively. 


\section{CONCLUSION}

The rising prevalence of r-type opacities in Appalachian coal miners suggests that respirable crystalline silica exposures in recent decades are an important factor in the resurgence of rapidly progressive and severe pneumoconiosis in the region. Effective technologies and best practices exist for controlling silica and other coal mine dust exposures. These measures must be properly applied and maintained to protect miners from developing this entirely preventable disease.

Acknowledgements The authors would like to acknowledge the work of the Coal Workers' Health Surveillance Program team as well as Emanuele Cauda and Laura Reynolds for their thoughtful review of manuscript drafts.

Contributors NBH: analysed and interpreted the data, led writing of the article and takes responsibility for its content. DJB and CNH: assisted with interpreting data and writing the article. ASL: conceptualised and designed the study and helped with data interpretation and writing.

Funding The authors have not declared a specific grant for this research from any funding agency in the public, commercial or not-for-profit sectors.

Competing interests None declared.

Ethics approval CWHSP is a public health surveillance programme with nonresearch designation and is exempt from NIOSH Human Subjects Review Board approval (11-DRDS-NRO3).

Provenance and peer review Not commissioned; externally peer reviewed.

\section{REFERENCES}

1 Laney AS, Petsonk EL, Attfield MD. Pneumoconiosis among underground bituminous coal miners in the United States: is silicosis becoming more frequent?. Occup Environ Med 2010;67:652-6.

2 Kuempel ED, Attfield MD, Vallyathan V, et al. Pulmonary inflammation and crystalline silica in respirable coal mine dust: dose-response. J Biosci 2003;28:61-9.
3 Cohen RA, Petsonk EL, Rose C, et al. Lung Pathology in U.S. Coal Workers with Rapidly Progressive Pneumoconiosis Implicates Silica and Silicates. Am J Respir Crit Care Med 2016;193:673-80.

4 Blackley DJ, Halldin CN, Laney AS. Continued Increase in Prevalence of Coal Workers' Pneumoconiosis in the United States, 1970-2017. Am J Public Health 2018;108:1220-2.

5 Almberg KS, Halldin CN, Blackley DJ, et al. Progressive Massive Fibrosis Resurgence Identified in U.S. Coal Miners Filing for Black Lung Benefits, 1970-2016. Ann Am Thorac Soc 2018;15:1420-6.

6 Blackley DJ, Halldin CN, Laney AS. Continued increase in lung transplantation for coal workers' pneumoconiosis in the United States. Am J Ind Med 2018;61:621-4.

7 Mazurek JM, Wood J, Blackley DJ, et al. Coal Workers' Pneumoconiosis-Attributable Years of Potential Life Lost to Life Expectancy and Potential Life Lost Before Age 65 Years - United States, 1999-2016. MMWR Morb Mortal Wkly Rep 2018;67:819-24.

8 International Labour Office. Guidelines for the use of the ILO international classification of radiographs of pneumoconioses. Geneva: International Labour Office, 2011.

9 Ruckley VA, Fernie JM, Chapman JS, et al. Comparison of radiographic appearances with associated pathology and lung dust content in a group of coalworkers. Br J Ind Med 1984;41:459-67.

10 Pollock DE, Gerald J. Joy: Investigation into dust exposures and mining practices in mines in the southern Appalachian Region. Mining Engineering 2010;62:44-9.

11 Reynolds LE, Blackley DJ, Colinet JF, et al. Work Practices and Respiratory Health Status of Appalachian Coal Miners With Progressive Massive Fibrosis. J Occup Environ Med 2018;60:e575-e581.

12 Blackley DJ, Reynolds LE, Short C, et al. Progressive Massive Fibrosis in Coal Miners From 3 Clinics in Virginia. JAMA 2018;319:500-1.

13 Laney AS, Attfield MD. Examination of potential sources of bias in the US Coal Workers' Health Surveillance Program. Am J Public Health 2014;104:165-70.

14 Cauda EC, Britton L, Fritz J. Mining Product: FAST - Field Analysis of Silica Tool. 2018 https://www.cdc.gov/niosh/mining/works/coversheet2056.html (Accessed 10 Feb 2018).

15 Almberg KS, Cohen RA, Blackley DJ, et al. Linking Compensation and Health Surveillance Data Sets to Improve Knowledge of US Coal Miners' Health. J Occup Environ Med 2017:59:930-4.

16 Reynolds L, Halldin CN, Laney AS, et al. Coal miner participation in a job transfer program designed to prevent progression of pneumoconiosis, United States, 1986-2016. Arch Environ Occup Health 2018;73:344-6. 